\title{
Article \\ Lipoprotein(a), Immune Cells and Cardiovascular Outcomes in Patients with Premature Coronary Heart Disease
}

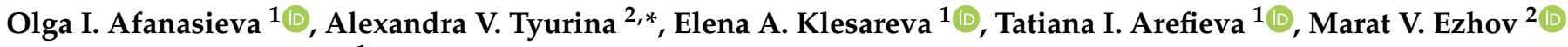 \\ and Sergei N. Pokrovsky ${ }^{1}$ \\ 1 Institute of Experimental Cardiology, National Medical Research Center of Cardiology, \\ Ministry of Health of the Russian Federation, 121552 Moscow, Russia; afanasieva.cardio@yandex.ru (O.I.A.); \\ hea@mail.ru (E.A.K.); tiarefieva@cardio.ru (T.I.A.); dr.pokrovsky@mail.ru (S.N.P.) \\ 2 A.L. Myasnikov Institute of Clinical Cardiology, National Medical Research Center of Cardiology, \\ Ministry of Health of the Russian Federation, 121552 Moscow, Russia; marat_ezhov@mail.ru \\ * Correspondence: alex.tyurina.cardio@yandex.ru
}

\section{check for} updates

Citation: Afanasieva, O.I.; Tyurina, A.V.; Klesareva, E.A.; Arefieva, T.I.; Ezhov, M.V.; Pokrovsky, S.N. Lipoprotein(a), Immune Cells and Cardiovascular Outcomes in Patients with Premature Coronary Heart

Disease. J. Pers. Med. 2022, 12, 269.

https://doi.org/10.3390/

jpm12020269

Academic Editors: Yuliya I. Ragino and Akinori Nakamura

Received: 29 December 2021

Accepted: 10 February 2022

Published: 12 February 2022

Publisher's Note: MDPI stays neutral with regard to jurisdictional claims in published maps and institutional affiliations.

Copyright: (C) 2022 by the authors. Licensee MDPI, Basel, Switzerland. This article is an open access article distributed under the terms and conditions of the Creative Commons Attribution (CC BY) license (https:// creativecommons.org/licenses/by/ $4.0 /)$.

\begin{abstract}
The detection of lipoprotein(a) $[\mathrm{Lp}(\mathrm{a})]$ in the artery wall at the stage of lipid-bands formation may indicate that it participates in the atherosclerosis local nonspecific inflammatory process. Innate immune cells are involved in atherogenesis, with monocytes playing a major role in the initiation of atherosclerosis, while neutrophils can contribute to plaque destabilization. This work studies the relationship between Lp(a), immune blood cells and major adverse cardiovascular events (MACE) in patients with the early manifestation of coronary heart disease (CHD). The study included 200 patients with chronic CHD, manifested up to the age of 55 in men and 60 in women. An increased Lp(a) concentration [hyperLp(a)] was shown to predict cardiovascular events in patients with premature $\mathrm{CHD}$ with long-term follow-up. According to the logistic regression analysis results, an increase in the monocyte count with OR $=4.58$ (95\% CI 1.04-20.06) or lymphocyte-to-monocyte ratio with OR $=0.82$ (0.68-0.99), ( $p<0.05$ for both) was associated with MACE in patients with early CHD, regardless of gender, age, classical risk factors, atherogenic lipoproteins concentration and statin intake. The combination of an increased monocyte count and hyperLp(a) significantly increased the proportion of patients with early CHD with subsequent development of MACE ( $p=0.02, p$ trend $=0.003$ ). The odds of cardiovascular events in patients with early CHD manifestation were highest in patients with an elevated lymphocyte-to-monocyte ratio and an elevated Lp(a) level. A higher neutrophil blood count and an elevated neutrophil-to-lymphocyte ratio determined the faster development of MACE in patients with a high $\mathrm{Lp}$ (a) concentration. The data obtained in this study suggest that the high atherothrombogenicity of $\mathrm{Lp}(\mathrm{a})$ is associated with the "inflammatory" component and the innate immune cells involvement in this process. Thus, the easily calculated immunological ratios of blood cells and $\mathrm{Lp}(\mathrm{a})$ concentrations can be considered simple predictors of future cardiovascular events.
\end{abstract}

Keywords: lipoprotein(a); immune cells blood count; coronary heart disease

\section{Introduction}

Atherosclerotic cardiovascular diseases (ASCVDs) have remained the leading cause of death worldwide over the past 15 years, despite continued advances in pharmaceuticals and technology [1]. Although there is some progress in the treatment of cardiovascular disease, a trend towards the earlier development of ASCVD and associated cardiovascular events can be observed [2-5]. A significant proportion of major adverse cardiovascular events (MACE) could be avoided via the correction of modifiable risk factors [6], but despite this, the residual risk of CVD development remains [7].

Signs of the local nonspecific inflammatory process in atherosclerosis are traced from the earliest stages of the vessel-wall-lesion development to the stage of destabilization and atherosclerotic plaque damage $[8,9]$. There is a growing body of evidence supporting the 
idea that lipoprotein(a) [Lp(a)] and inflammation are important factors in residual risk of ASCVD development [10]. The structural organization of Lp(a), the genetic nature of $\mathrm{Lp}$ (a) levels inheritance and its presence in the walls of the arteries already at the stage of lipid-band formation suggested it can participate in this inflammatory process. Several types of immune cells are involved in the atherosclerotic process, such as monocytes, $\mathrm{T}$ and B lymphocytes, neutrophils. The results of some studies have shown that enhanced myelopoiesis plays a central role in increasing monocyte and neutrophil numbers in cardiovascular disease and intensifies the formation of atherosclerotic lesions [11]. Despite exploring Lp(a) for several decades, many aspects regarding its role in the development of atherosclerosis are still unclear. There are data that $\mathrm{Lp}(\mathrm{a})$ is able to enhance the production of inflammatory monocytes in the bone marrow [12]. We have recently shown that in patients with an elevated Lp(a) level, the absolute and relative content of non-classical CD14+CD16++ monocytes is significantly higher [13], indicating the ability of Lp(a) to influence monocytes. Residual cardiovascular risk in patients with atherosclerosis, despite adequate hypolipidemic therapy, could be related to the increased concentration of Lp(a) and, therefore, the possible relationship between $\mathrm{Lp}(\mathrm{a})$ and the vascular wall inflammation deserves further evaluation. Thus, the aim of this study is to investigate the association between $\mathrm{Lp}(\mathrm{a})$ concentration, immune blood cells count, and cardiovascular outcomes in patients with early manifestation of coronary heart disease (CHD).

\section{Materials and Methods}

This retrospective study included consecutive patients who underwent a repeat examination at the National Medical Research Center of Cardiology of the Ministry of Health of the Russian Federation between 2019 and 2021 (Figure A1). The study was carried out in accordance with Good Clinical Practice and the principles of the Declaration of Helsinki. The study protocol was approved by the local ethics committee and written informed consent was obtained from all the patients before their enrollment. We included 200 patients aged $59 \pm 9$ years with a history of early CHD manifestation (before 55 and 60 years in men and women, respectively). Clinical charts were available from the time of manifestation of CHD for all the included patients. Exclusion criteria were severe comorbidities affecting the prognosis; dementia; alcohol abuse; autoimmune and infectious diseases; and treatment with any hormones, PCSK9 inhibitors, and apheresis. All the patients were examined and interviewed to evaluate the course of the disease and the presence of classical atherosclerosis risk factors. Arterial hypertension was diagnosed if the patient took antihypertensives, or in cases of of systolic blood pressure level being above $140 \mathrm{mmHg}$ and/or diastolic blood pressure being above $90 \mathrm{mmHg}$ according to two blood-pressure measurements on two different visits. Smoking status was assessed as never smoker, former smoker or current smoker [14]. Type 2 diabetes was diagnosed according to the World Health Organization criteria $[15,16]$. Body mass index (BMI) was calculated for all the participants and obesity was recorded at $\mathrm{BMI} \geq 30 \mathrm{~kg} / \mathrm{m}^{2}$.

The lipids (total cholesterol (TC), triglyceride (TG) and high-density lipoprotein cholesterol (HDL-C)) were determined by enzymatic colorimetric method on Hitachi 912 biochemical analyzers (Roche Diagnostics, Basal, Switzerland) and Architect C-8000 (Abbott, Abbott Park, Illinois, USA). The quality control of the studies was accomplished with the control sera Precinorm and Precipat (Roche Diagnostics, Basal, Switzerland). The low-density lipoprotein cholesterol (LDL-C) level was calculated with Martin-Hopkins's formula:

$$
\text { LDL-C }=\text { TC }- \text { HDL-C }-\frac{T G}{f},
$$

where $\mathrm{f}$ is an adjustable factor from 3.1 to 11.9 (result in $\mathrm{mg} / \mathrm{dL}$ ).

The concentration of LDL-C corrected for Lp(a)-cholesterol (LDL-C corr.) was calculated by Dahlen modification [17]:

$$
\mathrm{LDL}-\mathrm{C} \text { corr }=\mathrm{LDL}-\mathrm{C}-0.3 \times \frac{\mathrm{Lp}(a)}{38.7},(\text { result in } \mathrm{mmol} / \mathrm{L}) \text {, }
$$


Lp(a) concentration was determined using an enzyme immunoassay with sheep monospecific polyclonal antibodies against human L $(a)$, as previously described [18]. The sensitivity of the method was $0.2 \mathrm{mg} / \mathrm{dL}$, the intra-plate and between experiments variation coefficients were $3.8 \%$ and $9.8 \%$ in the $\mathrm{Lp}(\mathrm{a})$ concentration ranged from 5 to $190 \mathrm{mg} / \mathrm{dL}$. The method was validated with two kits, TintElize Lp(a) (Biopool AB, Umea, Sweden) and Immunozym Lp(a) (Progen Biotechnik GmbH, Heidelberg, Germany). The control serum (Technoclone, Vienna, Austria) was approved by the International Federation of Clinical Chemistry and was used to standardize the ELISA.

In addition, a routine blood test with the absolute count of leukocytes, the absolute and relative counts of lymphocytes, neutrophils, and monocytes was performed in all the patients. The lymphocyte-to-monocyte ratio (LMR) and neutrophil-to-lymphocyte ratio (NLR) were calculated as the ratios of the absolute count of lymphocyte to absolute count of monocyte and absolute count of neutrophil to absolute count of lymphocyte.

A statistical analysis was performed using a MedCalc 20.022. (MedCalc Software Ltd., Ostend, Belgium). The results were presented as a mean value \pm standard deviation or median with 25th and 75th percentiles for normal or abnormal distribution according to Kolmogorov-Smirnov test, respectively. Student's parametric t-test and non-parametric Mann-Whitney test were used when comparing the quantitative data of the two groups. Fischer's exact test was used to estimate frequency data between groups. The Spearman rank correlation and multiple regression or logistic analysis were used. Odds ratio (OR) and 95\% confidence intervals (CI) were calculated to evaluate associations between outcomes and study parameters. ROC-analysis was conducted to determine the cut-off criterion of $\mathrm{Lp}$ (a) level or lymphocyte-to-monocyte or neutrophil-to-lymphocyte ratios and associated sensitivity and specificity for MACE. Apart from that, and the Kaplan-Meier survival curve was analyzed because parameters such as sex, age of CHD manifestation, statin medication, and hyperLp(a) ( $\geq 30 \mathrm{mg} / \mathrm{dL})$, remained unchanged during the whole time from CHD manifestation until now.

\section{Results}

Most of the patients were males $(n=166,83 \%)$. Arterial hypertension was observed in $87 \%$ of the patients, type 2 diabetes in $30 \%$, and $63 \%$ were current or former smokers. All the patients took statins at an adequate dose, the average dose equivalent to atorvastatin was $43.4 \pm 21.3 \mathrm{mg}$. Another therapy is presented in the Table A1.

Over the median follow-up of 12 years, starting from the time of CHD manifestation in 121 out of 200 patients, the following major adverse cardiovascular events (MACE) were distinguished: non-fatal myocardial infarction $(n=57,29 \%)$, coronary artery bypass grafting $(n=65,33 \%)$, hospitalizations for unstable angina $(n=35,18 \%)$, and ischemic stroke $(n=14,7 \%)$.

There were no differences in terms of age, gender, classical risk factors frequency, baseline levels of TC, TG, HDL-C or LDL-C, hypolipidemic and antiplatelet therapy in the studied groups (Table 1 ).

The concentration of $\mathrm{Lp}(\mathrm{a})$ was higher in the patients with MACE in comparison with the group without MACE: $44[13 ; 98] \mathrm{mg} / \mathrm{dL}$ and $25[8 ; 79] \mathrm{mg} / \mathrm{dL}$, respectively, $p<0.05$ (Figure 1).

According to ROC-analysis, the concentration of $\mathrm{Lp}(\mathrm{a}) \geq 30 \mathrm{mg} / \mathrm{dL}$ was associated with MACE with $60 \%$ sensitivity and $54 \%$ specificity (area under the curve $0.59 ; 95 \%$ CI $0.51-0.65 ; p<0.05)$. The ROC analysis for the two cut-off points-30 and $50 \mathrm{mg} / \mathrm{dL}-$ showed no significant differences, but the AUC was slightly higher for the cut-off point $30 \mathrm{mg} / \mathrm{dL}$ vs. $50 \mathrm{mg} / \mathrm{dL}: 0.57 ; 0.50-0.64$ vs. $0.56 ; 0.49-0.63, p>0.05$.

The level of $\mathrm{Lp}(\mathrm{a}) \geq 30 \mathrm{mg} / \mathrm{dl}$ detected in $60 \%$ of the patients with early manifestation of CHD and MACE in comparison with $45 \%$ of the patients without MACE is presented, with $p<0.05$ (Figure 2). The OR of MACE in patients with Lp(a) concentration of $\geq 30 \mathrm{mg} / \mathrm{dL}$ was $1.25(0.99-1.58), p=0.06$. 
Table 1. The patients' characteristics depending on the occurrence of MACE.

\begin{tabular}{cccc}
\hline & $\begin{array}{c}\text { without MACE } \\
n=79\end{array}$ & $\begin{array}{c}\text { MACE } \\
n=\mathbf{1 2 1}\end{array}$ & $\boldsymbol{p}$-Value \\
\hline Men & $61(77 \%)$ & $105(87 \%)$ & 0.1 \\
\hline Age, years & $57.6 \pm 8.5$ & $59.5 \pm 9.0$ & 0.5 \\
\hline Age of CHD manifestation, years & $47.7 \pm 6.8$ & $45.9 \pm 7.9$ & 0.2 \\
\hline BMI, kg/m ${ }^{2}$ & $29.4 \pm 6.3$ & $30.0 \pm 5.0$ & 0.5 \\
\hline Follow-up, years & $10 \pm 7$ & $13 \pm 8$ & 0.4 \\
\hline Obesity & $45(57 \%)$ & $57(47 \%)$ & 0.2 \\
\hline Arterial hypertension & $70(89 \%)$ & $102(84 \%)$ & 0.6 \\
\hline Smoking & $47(60 \%)$ & $79(65 \%)$ & 0.5 \\
\hline Family history of CVD & $32(41 \%)$ & $39(32 \%)$ & 0.3 \\
\hline Type 2 diabetes & $25(32.6 \%)$ & $35(29 \%)$ & 0.8 \\
\hline TC, mmol/L & $4.3 \pm 1.2$ & $4.3 \pm 1.1$ & 1.0 \\
\hline TG, mmol/L & $1.5[1.1 ; 2.1]$ & $1.5[1.1 ; 2.2]$ & 1.0 \\
\hline HDL-C, mmol/L & $1.1 \pm 0.3$ & $1.2 \pm 0.3$ & 0.9 \\
\hline LDL-C, mmol/L & $2.5 \pm 1.1$ & $2.4 \pm 1.0$ & 0.4 \\
\hline LDL-C corr, mmol/L & $2.2 \pm 1.1$ & $1.8 \pm 1.1$ & 0.1 \\
\hline Average dose of statins, mg & $42 \pm 20$ & $45 \pm 22$ & 0.3 \\
\hline LDL-C < 1.4 mmol/L & $10(13 \%)$ & $14(12 \%)$ & 0.8 \\
\hline Antiplatelet/anticoagulant & $65(82 \%)$ & $101(83 \%)$ & 1.0 \\
\hline
\end{tabular}

Data are presented as mean \pm standard deviation, or median $[25 \% ; 75 \%]$, or $n(\%)$.

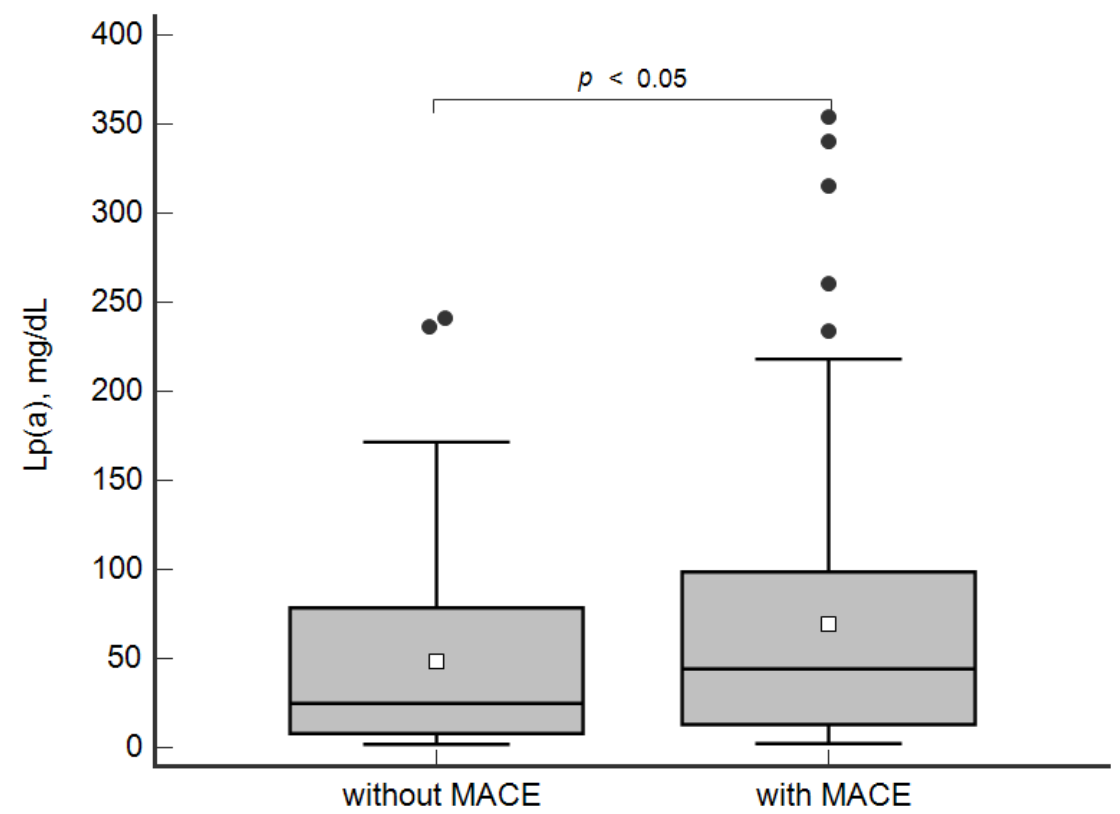

Figure 1. Concentration of lipoprotein(a) in patients with and without MACE. Data are presented as Box-and-Whisker plot: a grey box is drawn from the $25 \%$ and $75 \%$; a horizontal line is a median $(50 \%)$, a white square symbol is a mean, black points are values to the above of $1.5 \times$ IQR (the Interquartile range (IQR) is calculated as $75 \%-25 \%$ ). 


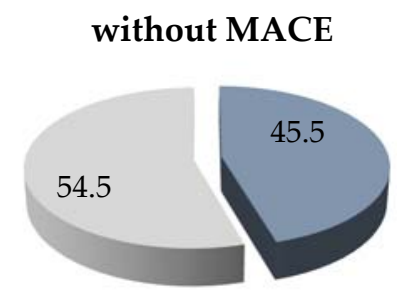

$$
p<0.05
$$

MACE

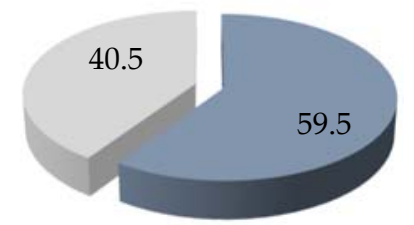

- $\mathrm{Lp}(\mathrm{a}) \geq 30 \mathrm{mg} / \mathrm{dL} \quad \mathrm{Lp}(\mathrm{a})<30 \mathrm{mg} / \mathrm{dL}$

Figure 2. The proportion of patients with $\mathrm{Lp}(\mathrm{a}) \geq 30 \mathrm{mg} / \mathrm{dL}$ in groups with and without MACE.

A trend towards a more rapid development of MACE was detected in the patients with $\mathrm{Lp}(\mathrm{a}) \geq 30 \mathrm{mg} / \mathrm{dL}$. The patients without MACE but with $\mathrm{Lp}(\mathrm{a}) \geq 30 \mathrm{mg} / \mathrm{dL}$ had a mean survival time of $143 \pm 15$ months versus $168 \pm 18$ months in those with Lp(a) $<30 \mathrm{mg} / \mathrm{dL}, p<0.01$ (Figure A2).

The blood-cells count did not significantly differ in the patients with and without MACE (Table 2).

Table 2. Blood cells counts in patients with and without MACE.

\begin{tabular}{cccc}
\hline & $\begin{array}{c}\text { without MACE } \\
n=79\end{array}$ & $\begin{array}{c}\text { MACE } \\
n=121\end{array}$ & $p$-Value \\
\hline Leukocytes, $10^{9} / \mathrm{L}$ & $7.8[6.6 ; 9.2]$ & $7.7[6.3 ; 8.9]$ & 0.64 \\
\hline Lymphocytes, $10^{9} / \mathrm{L}$ & $2.2[1.7 ; 2.9]$ & $2.0[1.6 ; 2.5]$ & 0.12 \\
\hline Lymphocytes, $\%$ & $28.9[24.4 ; 35.5]$ & $27.5[22.3 ; 33.2]$ & 0.10 \\
\hline Neutrophils, $10^{9} / \mathrm{L}$ & $4.7[3.7 ; 5.5]$ & $4.5[3.8 ; 5.7]$ & 0.85 \\
\hline Neutrophils, $\%$ & $59.8[53.8 ; 64.9]$ & $61.8[55.8 ; 67.7]$ & 0.14 \\
\hline Monocytes, $10^{9} / \mathrm{L}$ & $0.5[0.4 ; 0.6]$ & $0.6[0.4 ; 0.7]$ & 0.20 \\
\hline Monocytes, $\%$ & $6.8[5.4 ; 8.1]$ & $7.0[5.9 ; 9.2]$ & 0.09 \\
\hline Basophiles, $10^{9} / \mathrm{L}$ & $0.07[0.05 ; 0.09]$ & $0.06[0.05 ; 0.09]$ & 0.50 \\
\hline Basophils, $\%$ & $0.90[0.68 ; 1.16]$ & $0.87[0.58 ; 1.10]$ & 0.37 \\
\hline Eosinophils, $10^{9} / \mathrm{L}$ & $0.2[0.1 ; 0.3]$ & $0.14[0.07 ; 0.21]$ & 0.12 \\
\hline Eosinophils, $\%$ & $2.2[1.1 ; 3.2]$ & $1.7[1.0 ; 2.7]$ & 0.20 \\
\hline Platelets, $10^{9} / \mathrm{L}$ & $220.0[195.5 ; 268.0]$ & $210.0[177.0 ; 251.3]$ & 0.04 \\
\hline
\end{tabular}

Data are presented as median [25\%;75\%].

A correlation analysis showed no significant associations between immune-blood cells count and $\mathrm{Lp}$ (a) concentrations or other atherogenic lipoproteins.

According to the logistic regression analysis, an increase in $\mathrm{Lp}(\mathrm{a})$ concentration by $10 \mathrm{mg} / \mathrm{dL}$ with OR $=1.06$ (95\% CI 1.00-1.14), age increase by one year with OR $=1.04$ $(1.00-1.08)$ and male sex of the patients with $\mathrm{OR}=2.57$ (1.07-6.19) were independently associated with MACE, regardless of other risk factors, lipids, and the monocytes count.

The combination of an elevated monocyte count (above median) in the presence of $\mathrm{Lp}(\mathrm{a}) \geq 30 \mathrm{mg} / \mathrm{dL}$ significantly increased the proportion of the patients with MACE $\left(p=0.02, p_{\text {trend }}=0.003\right)$ (Figure 3$)$. 


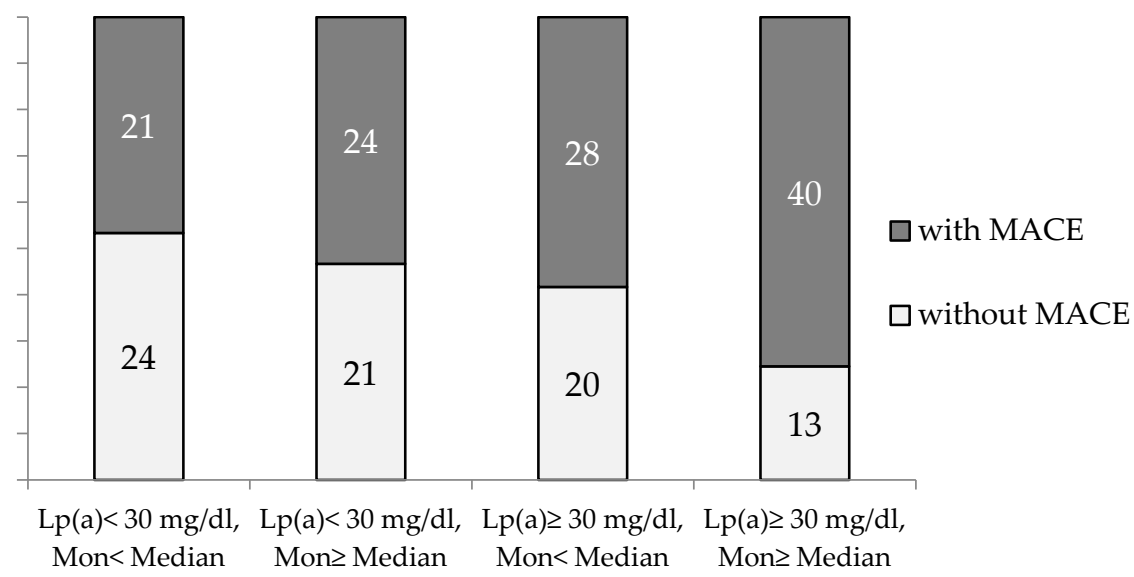

Figure 3. The proportion of CHD patients with and without MACE during observation period depends on blood monocyte count and Lp(a) concentration. Mon-monocytes. Median for Mon $=0.54 \times 10^{9} / \mathrm{L}$.

The lymphocyte-to-monocyte ratio was lower in the group of the patients with MACE during the observation period $3.9 \pm 2.5$ vs. $4.6 \pm 1.9, p=0.05$. According to the ROC analysis, the lymphocyte-to-monocyte ratio was significantly associated with MACE (AUC $=0.61, p=0.01$ ) and the cut-off value was calculated as $<4.56$ (a sensitivity of $69 \%$ and a specificity $49 \%$ ). The median of the distribution for the lymphocyte-to-monocyte ratio was 4.18 . This value discriminates MACE with a sensitivity of $60 \%$ and a specificity of $55 \%$ and was chosen as the most suitable for the proceeding calculations.

The combination of the reduced lymphocyte-to-monocyte ratio with $\mathrm{Lp}(\mathrm{a}) \geq 30 \mathrm{mg} / \mathrm{dL}$ was found in $34 \%$ of the patients with MACE vs. $19 \%$ in the patients without MACE (Figure 4) and significantly increased the chance of developing MACE in such patients (Table 3).
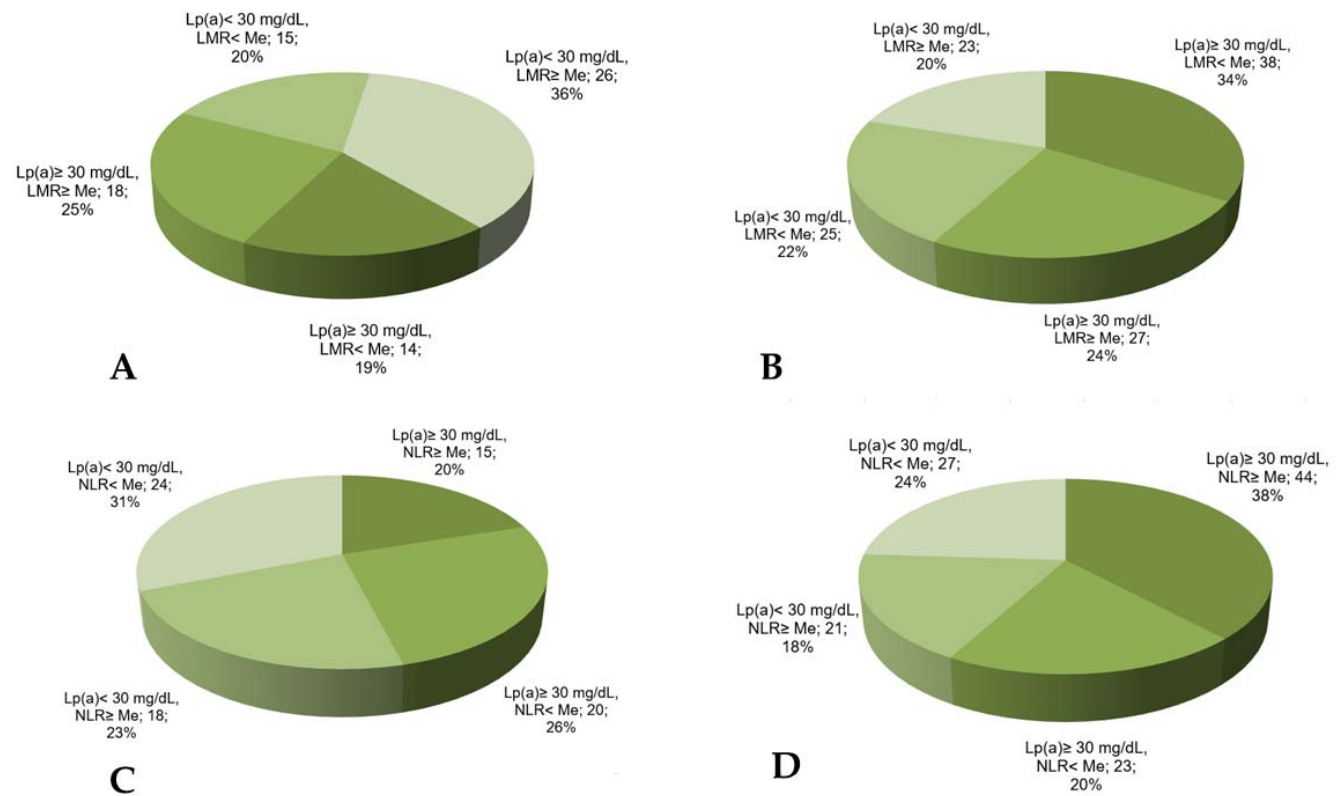

Figure 4. The proportion of CHD patients according to Lp(a) concentration, lymphocyte-to-monocyte ratio, or neutrophil-to-lymphocyte ratio in groups without $(\mathbf{A}, \mathbf{B})$ or with $(\mathbf{C}, \mathbf{D})$ MACE. LMRlymphocyte-to-monocyte ratio, NLR-neutrophil-to-lymphocyte ratio, Me-median. Median for $\mathrm{LMR}=4.18$, for NLR $=2.66$. 
Table 3. MACE odds ratio in patients depending on $\mathrm{Lp}(\mathrm{a})$ concentration and blood immune cell distribution according to the median.

\begin{tabular}{ccc}
\hline & Lp(a) $<30 \mathbf{~ m g} / \mathbf{d L}$ & Lp(a) $\geq \mathbf{3 0 ~} \mathbf{~ m} / \mathbf{d L}$ \\
\hline Monocytes $<0.54 \times 10^{9} / \mathrm{L}$ & 1 & $1.22(0.53-2.78)$ \\
\hline Monocytes $\geq 0.54 \times 10^{9} / \mathrm{L}$ & $1.0(0.44-2.28)$ & $2.69(1.14-6.34) *$ \\
\hline LMR $\geq 4.18$ & 1 & $1.70(0.75-3.85)$ \\
\hline LMR $<4.18$ & $1.88(0.80-4.41)$ & $3.07(1.33-7.04) *$ \\
\hline Neutrophils $<5.04 \times 10^{9} / \mathrm{L}$ & 1 & $1.38(0.59-3.21)$ \\
\hline Neutrophils $\geq 5.04 \times 10^{9} / \mathrm{L}$ & $0.76(0.33-1.74)$ & $1.65(0.96-4.92)$ \\
\hline NLR $<2.66$ & 1 & $1.02(0.45-2.30)$ \\
\hline NLR $\geq 2.66$ & $1.04(0.45-1.10)$ & $2.61(1.17-5.82) *$ \\
\hline${ }^{*} p<0.05 ;$ LMR-lymphocyte-to-monocyte ratio, NLR-neutrophil-to-lymphocyte ratio.
\end{tabular}

The neutrophil-to-lymphocyte ratio has no significant association with MACE (AUC $=0.56, p=0.07$ ) according to the ROC analysis. Nevertheless, the proportion of the patients with $\mathrm{Lp}(\mathrm{a}) \geq 30 \mathrm{mg} / \mathrm{dL}$ and the neutrophil-to-lymphocyte ratio above the median was maximal in the patients with MACE (Figure 4).

According to the logistic-regression analysis, an increase in the lymphocyte-to-mono cyte ratio per unit was associated with MACE in the patients with the early CHD manifestation regardless of their sex, age, risk factors (arterial hypertension, diabetes, smoking), lipid levels, and statin intake $(\mathrm{OR}=0.8(0.7-1.0), p=0.04)$. The neutrophils count and neutrophil-to-lymphocyte ratio were not associated with MACE in the same model.

However, in the subgroup of the patients with neutrophil-to-lymphocyte ratio and neutrophils count above the median, the $\mathrm{Lp}(\mathrm{a})$ concentration $\geq 30 \mathrm{mg} / \mathrm{dL}$ significantly reduced the mean survival time for MACE, in contrast to the subgroup of the patients with neutrophils count below the median (Figures 5 and 6).

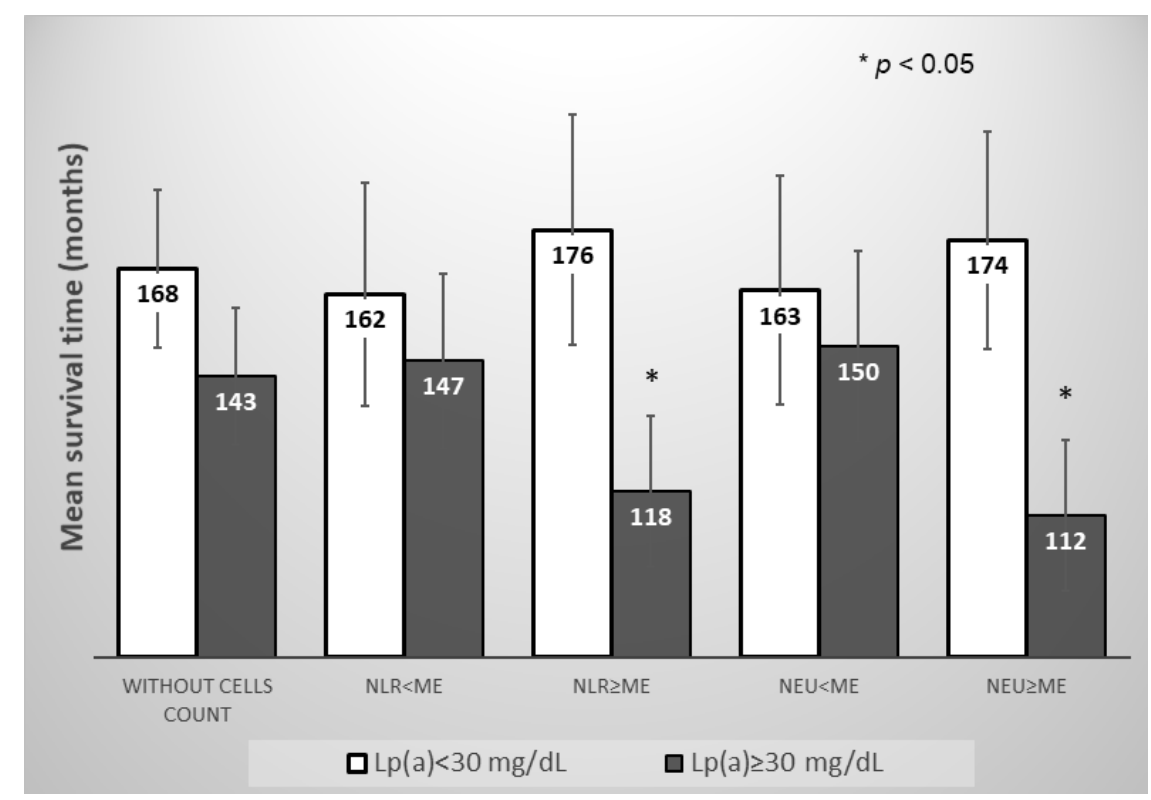

Figure 5. Mean survival time without MACE in subgroups of patients depending on the of Lp(a) concentration, the neutrophils blood count, or the neutrophil-to-lymphocyte ratio. NLR-neutrophil-tolymphocyte ratio, NEU—neutrophil, Me-median. Median for NLR = 2.66, for Neu $=5.04 \times 10^{9} / \mathrm{L}$. 

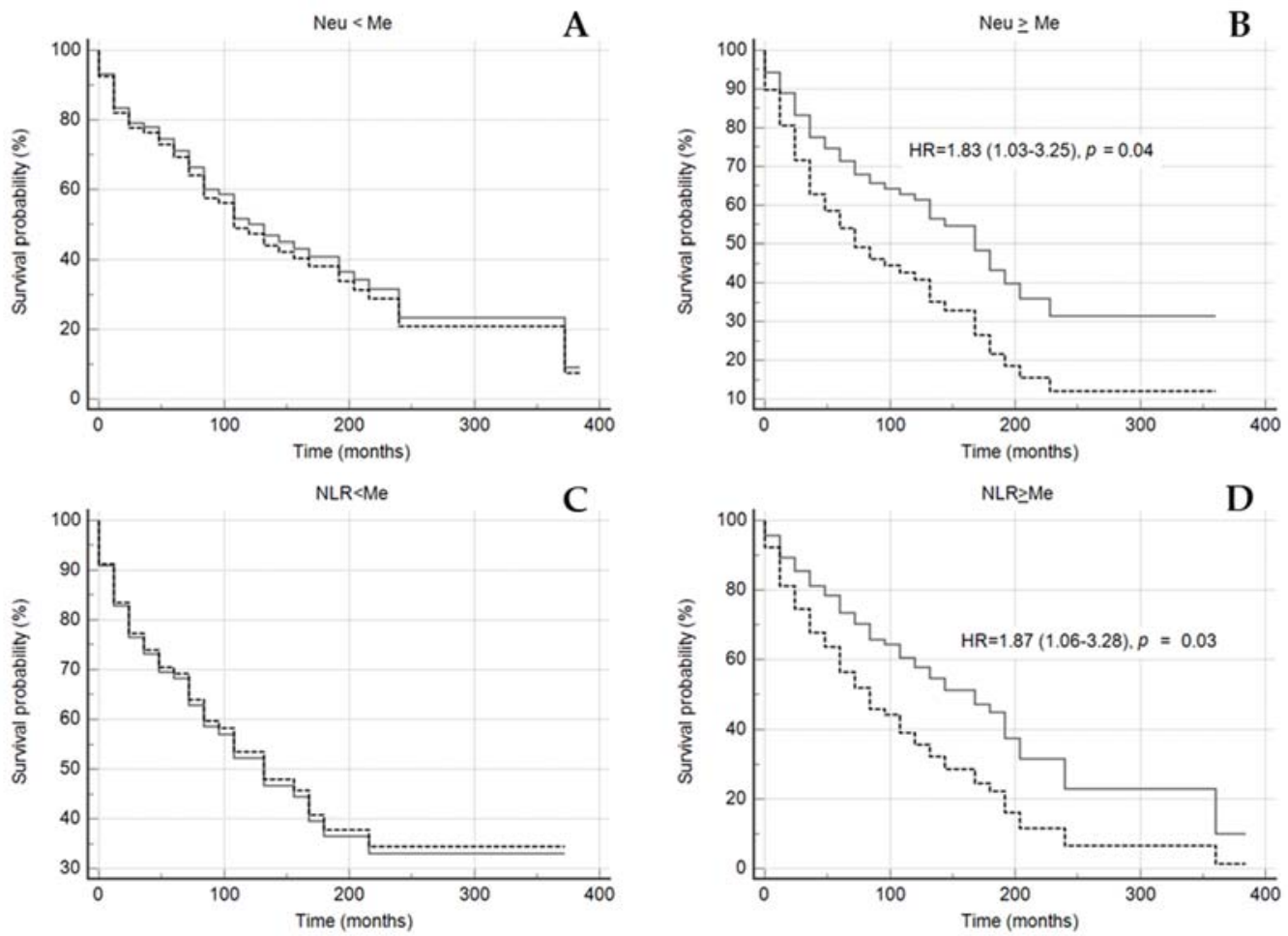

Figure 6. Kaplan-Meier survival without events curves in subgroups of patients with neutrophils count $<$ median (A) or $\geq$ median (B), NLR $<$ median (C) or $\geq$ median (D) depending on the of $\mathrm{Lp}(\mathrm{a})<30 \mathrm{mg} / \mathrm{dL}$ (grey solid line) and Lp(a) $\geq 30 \mathrm{mg} / \mathrm{dL}$ (black dotted line). NLR-neutrophil-tolymphocyte ratio, NEU—neutrophil, Me-median. Median for NLR 2.66, for Neu $5.04 \times 10^{9} / \mathrm{L}$. Sex, age of CHD manifestation, statin medication was included in model of Cox proportional regression.

\section{Discussion}

The hypothesis that $L p(a)$ pathogenicity is associated with inflammation and that immune cells, and monocytes in particular, are involved, was expressed quite a long time ago [19]. The relationship between the innate immune system and $L p(a)$ is based on the fact that oxidized phospholipids localized on $\mathrm{Lp}(\mathrm{a}) \mathrm{can}$ be recognized by receptors of innate immunity [20].

Inflammation in the arterial vessel wall is detected in subjects with increased concentration of $\mathrm{Lp}(\mathrm{a})$. In contrast, monocytes isolated from the blood of patients with a high concentration of $\mathrm{Lp}(\mathrm{a})$ demonstrate an increased ability to transendothelial migration [21].

The activation of the innate immune system in patients with hyperlipoproteinemia(a) is consistent with our recent study, which demonstrated that in patients with an elevated Lp(a) concentration, there is a redistribution of monocyte subpopulations towards an increase in CD14+CD16++ monocytes [13]. Furthermore, the combination of hyperlipoproteinemia(a) and a higher content of intermediate monocytes was associated with a significant increase in stenotic plaques in all major coronary arteries.

The results of this retrospective study, in which patients with early CHD manifestation participated, showed that an increased monocyte count on the background of hyperlipoproteinemia(a) is associated with a 2.7-fold increase in the chance of MACE developing compared to those with $\mathrm{Lp}(\mathrm{a})<30 \mathrm{mg} / \mathrm{dl}$ and the monocyte count below the median.

Experiments on apoE-/- mice demonstrated that myocardial infarction caused by artery ligation leads to an accelerated accumulation of innate immune cells, namely, an increase in both the total number of monocytes/macrophages in the aorta and a subpopulation of pro-inflammatory monocytes with a high content of Ly-6C as well as larger atherosclerotic lesions with a more advanced morphology relative to individuals without myocardial infarction [22]. The secreted pro-inflammatory cytokines by activated mono- 
cytes can accelerate the atherosclerotic process and contribute to the further destabilization of atherosclerotic plaques.

The neutrophil-to-lymphocyte ratio, as a possible marker of chronic systemic inflammation, is a simple predictor for both cardiovascular events and cardiovascular death in large prospective observational studies [23,24].

In our study, a neutrophil-to-lymphocyte ratio of more than 2.66 with an elevated $\mathrm{Lp}$ (a) concentration showed a twofold chance of MACE in patients with early CHD manifestation. A faster onset of MACE was demonstrated in patients with $\mathrm{Lp}(\mathrm{a})>30 \mathrm{mg} / \mathrm{dL}$ and elevated neutrophil blood count or neutrophil-to-lymphocyte ratio. However, the correlation between $\mathrm{Lp}(\mathrm{a})$ concentration and neutrophils was not detected. Moreover, a correlation between HDL-C and neutrophil-to-lymphocyte ratio that has been described for healthy subjects, was not found in the patients with early manifestation of CHD [25].

Neutrophil-to-lymphocyte ratio as a marker of systemic inflammation has no specificity and is of prognostic value in oncology, sepsis, and other conditions [26,27]. However, a growing body of evidence demonstrates that neutrophils play an integral role in atherosclerotic cardiovascular disease development. The ability of neutrophils to enhance monocyte adhesion and transmigration to atherosclerotic plaques may contribute to a more severe atherosclerotic process in patients with an elevated Lp(a) level and early manifestation of CHD. There is evidence that neutrophils are localized near plaques that are prone to rupture [28]. Previously, it has been shown that the concentration of matrix metalloproteinase 9 was positively associated with the size of the necrotic core of atherosclerotic plaques and was inversely related to the fibrous tissue content of the plaques in patients with chronic CHD and Lp(a) level $>60 \mathrm{mg} / \mathrm{dL}$ [29]. The secretion of active proteases by neutrophils metalloproteinase 9, which degrades the fibrous capsule, may also explain the effects of neutrophils on MACE development in patients with elevated Lp(a) concentrations.

Despite the prominent role of both dyslipidemia and inflammation as crucial factors in atherogenesis [30], the diversity and sequence of inflammatory processes and the involvement of atherogenic lipoproteins are still unclear.

All the patients in the present study took statins, but most patients had MACE during a median of 12 years of follow-up, and the groups did not differ in terms of LDL-C concentration.

Patients with early CHD belong to the category of very high cardiovascular risk, which may explain the high percentage of cases with MACE during prolonged observation. In addition, in $78 \%$ of patients CHD has been manifested with myocardial infarction, which significantly worsens the prognosis. There are identical results for the high 15-year mortality in patients with early myocardial infarction in a long-term survival study [31]. Overall, 65\% of patients had at least one serious cardiovascular event and/or death in the study Yagel and colleagues, examining cardiovascular outcomes in patients with early acute coronary syndrome [32]. More, than half (52.9\%) of patients with early CHD had at least one cardiovascular event during 10 years of follow-up in another study of long-term prognosis [33]. The observation period in our study was more than 12 years for $50 \%$ and more than 18 years for $25 \%$ of included patients.

Male gender is a risk factor for cardiovascular diseases, especially for early CHD manifestation, and the number of men in our study was higher than the number of women. This corresponded with the prospective observational cohort study GENESIS-PROXY (Gender and Sex determinants of cardiovascular disease: from bench to beyond-Premature Acute Coronary Syndrome) [34] and another study devoted to the long-term prognosis in patients with early coronary heart disease [33]. In the study of risk profiles, sex-related differences, and outcomes in a contemporary population of young patients with CAD, men also made up $70 \%$ of the study group [5].

Although the existing effective methods of lipid-lowering therapy significantly reduce the burden of cardiovascular diseases, their effect on inflammation is contradictory. The results of a post hoc analysis of the FOURIER study showed that patients with a CRP level $>2 \mathrm{mg} / \mathrm{L}$ had a higher risk of MACE compared to participants with normal CRP 
levels, despite achieving the target LDL-C levels [35]. The risk associated with an increased Lp(a) concentration was also significantly higher in patients with more pronounced inflammation and higher CRP $>2 \mathrm{mg} / \mathrm{L}$ [36].

A reduction of cardiovascular events risk while taking anti-inflammatory drugs has been demonstrated in several clinical studies-Canakinumab Anti-inflammatory Thrombosis Outcome Study (CANTOS) that used therapeutic monoclonal antibodies against IL-1 $\beta$ (canakinumab), and LoDoCo2 study where low doses of colchicine in patients with chronic CHD were used [37,38].

We hypothesize a relationship between chronic inflammation processes, $\mathrm{Lp}(\mathrm{a})$ concentrations, and the development of MACE. The clinical significance of the present study results is related to the fact that patients with early CHD manifestation and elevated $\mathrm{Lp}(\mathrm{a})$ chronic inflammation, expressed as an increased ratio of immune blood cells, are associated with a more severe disease. The ratios could be calculated from a routine blood test, and their association with a prospective prognosis for various diseases has been shown above [24]. We propose assessing such ratios in patients with early CHD manifestation, especially in patients with elevated Lp(a) levels. Elevated levels of circulating monocytes and neutrophils in patients with early CHD manifestation and subsequent MACE can provide a pool of inflammatory cells available for recruitment into the growing arteries and their secreted pro-inflammatory cytokines and can accelerate the atherosclerotic process and thus, contribute to further destabilization of atherosclerotic plaques, leading to the subsequent MACE.

\section{Study Limitation}

Our study has some limitations. Patients had CHD manifestation in the past, prior to enrolling in the study (median 12 years). Currently, all the patients are taking statins at adequate doses, but we have no precise data on the regularity of intake from the beginning of the disease to the present time. Because our study was retrospective, we cannot say that the neutrophils count, and the neutrophil-to-lymphocyte ratio were elevated at CHD manifestation. However, we assumed the relative stability of neutrophil blood counts and neutrophil-to-lymphocyte ratio by dividing the patients into subgroups according to these parameters and analyzing survival curves [23].

The ELISA method for Lp(a) determination was sensitive to apolipoprotein(a) isoforms, resulting in a slight increase in the $\mathrm{Lp}(\mathrm{a})$ concentration in samples with high molecular weight apo(a) isoforms. The absolute bias (median $[25 \% ; 75 \%]$ ) was $~ 1.5[-0.4 ; 5.7] \mathrm{mg} / \mathrm{dL}$. The high variability in the $\mathrm{Lp}(\mathrm{a})$ measurement, regardless of apo(a) isoforms, and the nonsignificant bias in the absolute Lp(a) concentration in our ELISA method makes it possible to assume that sensitivity of ELISA to apo(a) isoforms did not affect the results of the study. In addition, there were no significant differences in the $\mathrm{Lp}(\mathrm{a})$-associated relative risk of CAD in studies using methods both sensitive and insensitive to the size of apo(a) isoforms, according to meta-analysis [39].

According to the results of a recent prospective ACCELERATE trial, the significant association between an elevated $\mathrm{Lp}(\mathrm{a})$ concentration and time to first MACE was found in patients with CRP levels $\geq 2 \mathrm{mg} / \mathrm{L}$ [36]. We did not determine interleukin or C-reactive protein concentrations, which is also a limitation of the study.

\section{Conclusions}

An elevated Lp(a) concentration was shown to be a predictor of cardiovascular events in patients with premature $\mathrm{CHD}$ with long-term follow-up. The likelihood of cardiovascular events in patients with early CHD manifestation were highest in patients with an elevated lymphocyte-to-monocyte ratio and an elevated Lp(a) level. A higher neutrophil blood count and an elevated neutrophil-to-lymphocyte ratio determine the faster development of MACE in patients with a high $\mathrm{Lp}$ (a) concentration. Thus, the easily calculated immunological ratios of blood cells and Lp(a) concentration can be considered as simple predictors of future cardiovascular events. 
Author Contributions: Conceptualization, O.I.A., T.I.A., M.V.E.; writing-original draft preparation, O.I.A., A.V.T. investigation, A.V.T., E.A.K. writing-review and editing, T.I.A.; M.V.E., S.N.P. All authors have read and agreed to the published version of the manuscript.

Funding: The study was supported by Russian Science Foundation, project No. 22-25-00051.

Institutional Review Board Statement: The study was approved by the Ethics Committee of National Research Medical Center of Cardiology, Moscow, Russian Federation (protocol No. 251, 25 November 2019).

Informed Consent Statement: Informed consent was obtained from all subjects involved in the study.

Conflicts of Interest: The authors declare no conflict of interest.

\section{Appendix A}

Table A1. Therapy performed in the examined patients.

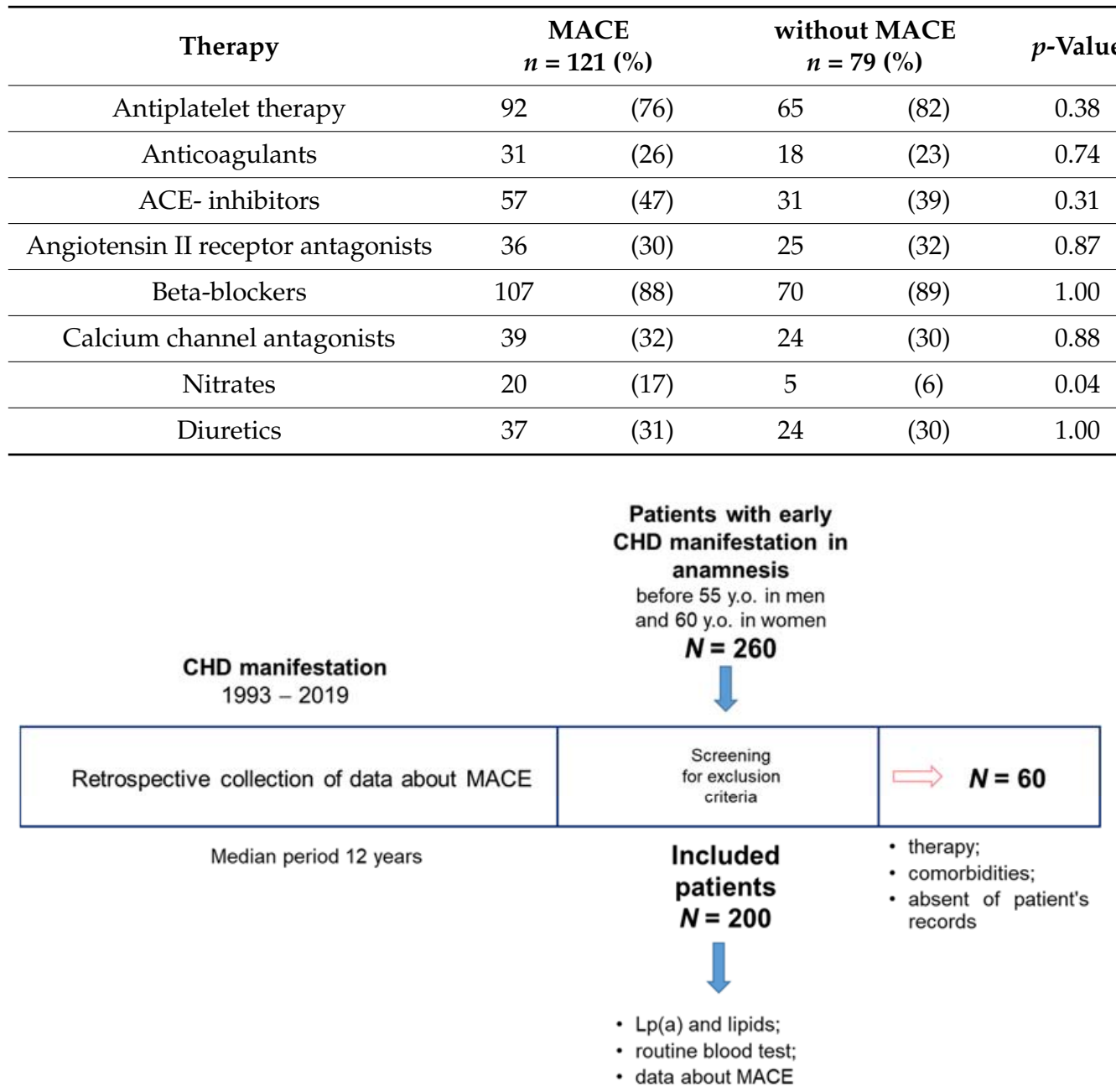

Figure A1. Design of the study. 260 patients with an early history of CHD hospitalized and screened between 2019 and 2021 were included during the screening phase. 60 people were expelled according to the exclusion criteria. The information about the presence or absence of any significant cardiovascular events as well as the date of each such event from the CHD manifestation was available for all patients according to medical records. All patients, after signing an informed consent, were re-examined, relevant medical data were collected, biochemical tests and routine blood tests were performed. 


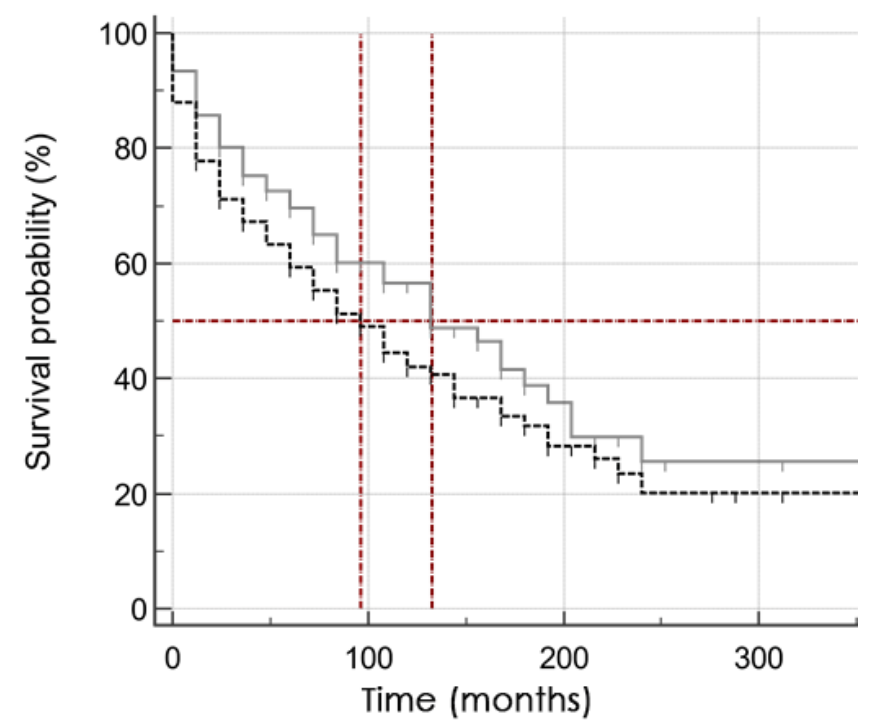

Figure A2. Kaplan-Meier survival curve in subgroups of patients $\mathrm{Lp}(\mathrm{a})<30 \mathrm{mg} / \mathrm{dL}$ (grey solid line) and $\mathrm{Lp}(\mathrm{a}) \geq 30 \mathrm{mg} / \mathrm{dL}$ (black dotted line). 50\% of patients in the group with elevated Lp(a) concentration lived to MACE after 96 (95\% CI 60-144) months vs. 132 months (95\% CI 84-192).

\section{References}

1. WHO. The Top 10 Causes of Death; World Health Organization: Geneva, Switzerland, 2018.

2. Andersson, C.; Vasan, R.S. Epidemiology of cardiovascular disease in young individuals. Nat. Rev. Cardiol. 2018, 15, 230-240. [CrossRef] [PubMed]

3. Maillet, A.; Desormais, I.; Rivière, A.B.; Aboyans, V.; Lacroix, P.; Mirault, T.; Messas, E.; Bataille, V.; Constans, J.; Boulon, C. Peripheral Atheromatous Arterial Disease in the Young: Risk Factors, Clinical Features, and Prognosis from the COPART Cohort. Angiology 2017, 68, 893-898. [CrossRef]

4. Tibæk, M.; Dehlendorff, C.; Jørgensen, H.S.; Forchhammer, H.B.; Johnsen, S.P.; Kammersgaard, L.P. Increasing Incidence of Hospitalization for Stroke and Transient Ischemic Attack in Young Adults: A Registry-Based Study. J. Am. Heart Assoc. 2016, 5, e003158. [CrossRef]

5. Vikulova, D.N.; Grubisic, M.; Zhao, Y.; Lynch, K.; Humphries, K.H.; Pimstone, S.N.; Brunham, L.R. Premature Atherosclerotic Cardiovascular Disease: Trends in Incidence, Risk Factors, and Sex-Related Differences, 2000 to 2016. J. Am. Heart Assoc. 2019, 8, e012178. [CrossRef]

6. Yusuf, S.; Joseph, P.; Rangarajan, S.; Islam, S.; Mente, A.; Hystad, P.; Brauer, M.; Kutty, V.R.; Gupta, R.; Wielgosz, A.; et al. Modifiable risk factors, cardiovascular disease, and mortality in 155,722 individuals from 21 high-income, middle-income, and low-income countries (PURE): A prospective cohort study. Lancet 2020, 395, 795-808. [CrossRef]

7. Cho, K.I.; Yu, J.; Hayashi, T.; Han, S.H.; Koh, K.K. Strategies to Overcome Residual Risk During Statins Era. Circ. J. Off. J. Jpn. Circ. Soc. 2019, 83, 1973-1979. [CrossRef] [PubMed]

8. Kaski, J.C.; Valenzuela Garcia, L.F. Therapeutic options for the management of patients with cardiac syndrome X. Eur. Heart J. 2001, 22, 283-293. [CrossRef]

9. Libby, P.; Ridker, P.M.; Maseri, A. Inflammation and atherosclerosis. Circulation 2002, 105, 1135-1143. [CrossRef]

10. Hoogeveen, R.C.; Ballantyne, C.M. Residual Cardiovascular Risk at Low LDL: Remnants, Lipoprotein(a), and Inflammation. Clin. Chem. 2021, 67, 143-153. [CrossRef]

11. Morgan, P.K.; Fang, L.; Lancaster, G.I.; Murphy, A.J. Hematopoiesis is regulated by cholesterol efflux pathways and lipid rafts: Connections with cardiovascular diseases. J. Lipid Res. 2020, 61, 667-675. [CrossRef]

12. Schnitzler, J.G.; Hoogeveen, R.M.; Ali, L.; Prange, K.H.M.; Waissi, F.; van Weeghel, M.; Bachmann, J.C.; Versloot, M.; Borrelli, M.J.; Yeang, C.; et al. Atherogenic Lipoprotein(a) Increases Vascular Glycolysis, Thereby Facilitating Inflammation and Leukocyte Extravasation. Circ. Res. 2020, 126, 1346-1359. [CrossRef] [PubMed]

13. Afanasieva, O.I.; Filatova, A.Y.; Arefieva, T.I.; Klesareva, E.A.; Tyurina, A.V.; Radyukhina, N.V.; Ezhov, M.V.; Pokrovsky, S.N. The Association of Lipoprotein(a) and Circulating Monocyte Subsets with Severe Coronary Atherosclerosis. J. Cardiovasc. Dev. Dis. 2021, 8, 63. [CrossRef] [PubMed]

14. Burki, T.K. WHO releases latest report on the global tobacco epidemic. Lancet. Oncol. 2021, 22, 1217. [CrossRef]

15. Classification of Diabetes Mellitus; World Health Organization: Geneva, Switzerland, 2019; Available online: https://apps.who.int/ iris/handle/10665/325182 (accessed on 1 December 2021).

16. Use of Glycated Haemoglobin (HbA1c) in the Diagnosis of Diabetes Mellitus; Abbreviated Report of a WHO Consultation (WHO/NMH/CHP/CPM/111); World Health Organization: Geneva, Switzerland, 2011. 
17. Dahlen, G.H. Incidence of Lp(a) lipoproteins among populations. In Lipoprotein(a); Scanu, A.M., Ed.; Academic Press: New York, NY, USA, 1990; pp. 151-173.

18. Afanasieva, O.I.; Ezhov, M.V.; Razova, O.A.; Afanasieva, M.I.; Utkina, E.A.; Pokrovsky, S.N. Apolipoprotein(a) phenotype determines the correlations of lipoprotein(a) and proprotein convertase subtilisin/kexin type 9 levels in patients with potential familial hypercholesterolemia. Atherosclerosis 2018, 277, 477-482. [CrossRef]

19. Kraaijenhof, J.M.; Hovingh, G.K.; Stroes, E.S.G.; Kroon, J. The iterative lipid impact on inflammation in atherosclerosis. Curr. Opin. Lipidol. 2021, 32, 286-292. [CrossRef]

20. Boffa, M.B.; Koschinsky, M.L. Oxidized phospholipids as a unifying theory for lipoprotein(a) and cardiovascular disease. Nat. Rev. Cardiol. 2019, 16, 305-318. [CrossRef]

21. van der Valk, F.M.; Bekkering, S.; Kroon, J.; Yeang, C.; Van den Bossche, J.; van Buul, J.D.; Ravandi, A.; Nederveen, A.J.; Verberne, H.J.; Scipione, C.; et al. Oxidized Phospholipids on Lipoprotein(a) Elicit Arterial Wall Inflammation and an Inflammatory Monocyte Response in Humans. Circulation 2016, 134, 611-624. [CrossRef]

22. Dutta, P.; Courties, G.; Wei, Y.; Leuschner, F.; Gorbatov, R.; Robbins, C.S.; Iwamoto, Y.; Thompson, B.; Carlson, A.L.; Heidt, T.; et al. Myocardial infarction accelerates atherosclerosis. Nature 2012, 487, 325-329. [CrossRef]

23. Adamstein, N.H.; MacFadyen, J.G.; Rose, L.M.; Glynn, R.J.; Dey, A.K.; Libby, P.; Tabas, I.A.; Mehta, N.N.; Ridker, P.M. The neutrophil-lymphocyte ratio and incident atherosclerotic events: Analyses from five contemporary randomized trials. Eur. Heart J. 2021, 42, 896-903. [CrossRef]

24. Balta, S.; Celik, T.; Mikhailidis, D.P.; Ozturk, C.; Demirkol, S.; Aparci, M.; Iyisoy, A. The Relation Between Atherosclerosis and the Neutrophil-Lymphocyte Ratio. Clin. Appl. Thromb. Hemost. 2016, 22, 405-411. [CrossRef]

25. Varol, E.; Bas, H.A.; Aksoy, F.; Ari, H.; Ozaydin, M. Relationship between neutrophil-lymphocyte ratio and isolated low high-density lipoprotein cholesterol. Angiology 2014, 65, 630-633. [CrossRef] [PubMed]

26. Guthrie, G.J.; Charles, K.A.; Roxburgh, C.S.; Horgan, P.G.; McMillan, D.C.; Clarke, S.J. The systemic inflammation-based neutrophil-lymphocyte ratio: Experience in patients with cancer. Crit. Rev. Oncol./Hematol. 2013, 88, 218-230. [CrossRef] [PubMed]

27. Ljungström, L.; Pernestig, A.K.; Jacobsson, G.; Andersson, R.; Usener, B.; Tilevik, D. Diagnostic accuracy of procalcitonin, neutrophil-lymphocyte count ratio, C-reactive protein, and lactate in patients with suspected bacterial sepsis. PLoS ONE 2017, 12, e0181704. [CrossRef] [PubMed]

28. Soehnlein, O. Multiple roles for neutrophils in atherosclerosis. Circ. Res. 2012, 110, 875-888. [CrossRef] [PubMed]

29. Ezhov, M.; Safarova, M.; Afanasieva, O.; Mitroshkin, M.; Matchin, Y.; Pokrovsky, S. Matrix Metalloproteinase 9 as a Predictor of Coronary Atherosclerotic Plaque Instability in Stable Coronary Heart Disease Patients with Elevated Lipoprotein(a) Levels. Biomolecules 2019, 9, 129. [CrossRef]

30. Libby, P.; Nahrendorf, M.; Swirski, F.K. Monocyte heterogeneity in cardiovascular disease. Semin. Immunopathol. 2013, 35, 553-562. [CrossRef] [PubMed]

31. Cole, J.H.; Miller, J.I., 3rd; Sperling, L.S.; Weintraub, W.S. Long-term follow-up of coronary artery disease presenting in young adults. J. Am. Coll. Cardiol. 2003, 41, 521-528. [CrossRef]

32. Yagel, O.; Shadafny, N.; Eliaz, R.; Dagan, G.; Leibowitz, D.; Tahiroglu, I.; Planer, D.; Amir, O.; Elbaz Greener, G.; Alcalai, R. Long-Term Prognosis in Young Patients with Acute Coronary Syndrome Treated with Percutaneous Coronary Intervention. Vasc. Health Risk Manag. 2021, 17, 153-159. [CrossRef]

33. Zeitouni, M.; Clare, R.M.; Chiswell, K.; Abdulrahim, J.; Shah, N.; Pagidipati, N.P.; Shah, S.H.; Roe, M.T.; Patel, M.R.; Jones, W.S. Risk Factor Burden and Long-Term Prognosis of Patients With Premature Coronary Artery Disease. J. Am. Heart Assoc. 2020, 9, e017712. [CrossRef]

34. Pilote, L.; Karp, I. GENESIS-PRAXY (GENdEr and Sex determInantS of cardiovascular disease: From bench to beyond-Premature Acute Coronary SYndrome). Am. Heart J. 2012, 163, 741-746. [CrossRef]

35. Bohula, E.A.; Giugliano, R.P.; Leiter, L.A.; Verma, S.; Park, J.G.; Sever, P.S.; Lira Pineda, A.; Honarpour, N.; Wang, H.; Murphy, S.A.; et al. Inflammatory and Cholesterol Risk in the FOURIER Trial. Circulation 2018, 138, 131-140. [CrossRef] [PubMed]

36. Puri, R.; Nissen, S.E.; Arsenault, B.J.; St John, J.; Riesmeyer, J.S.; Ruotolo, G.; McErlean, E.; Menon, V.; Cho, L.; Wolski, K.; et al. Effect of C-Reactive Protein on Lipoprotein(a)-Associated Cardiovascular Risk in Optimally Treated Patients With High-Risk Vascular Disease: A Prespecified Secondary Analysis of the ACCELERATE Trial. JAMA Cardiol. 2020, 5, 1136-1143. [CrossRef] [PubMed]

37. Nidorf, S.M.; Fiolet, A.T.L.; Mosterd, A.; Eikelboom, J.W.; Schut, A.; Opstal, T.S.J.; The, S.H.K.; Xu, X.F.; Ireland, M.A.; Lenderink, T.; et al. Colchicine in Patients with Chronic Coronary Disease. N. Engl. J. Med. 2020, 383, 1838-1847. [CrossRef]

38. Ridker, P.M.; Everett, B.M.; Thuren, T.; MacFadyen, J.G.; Chang, W.H.; Ballantyne, C.; Fonseca, F.; Nicolau, J.; Koenig, W.; Anker, S.D.; et al. Antiinflammatory Therapy with Canakinumab for Atherosclerotic Disease. N. Engl. J. Med. 2017, 377, 1119-1131. [CrossRef]

39. Erqou, S.; Kaptoge, S.; Perry, P.L.; Di Angelantonio, E.; Thompson, A.; White, I.R.; Marcovina, S.M.; Collins, R.; Thompson, S.G.; Danesh, J. Lipoprotein(a) concentration and the risk of coronary heart disease, stroke, and nonvascular mortality. JAMA 2009, 302, 412-423. [CrossRef] [PubMed] 